\title{
Prototype Helm Monitoring Udara Pada Industri Berbasis Internet Of Things
}

\author{
Alfie Syahri ${ }^{1}$ Ramadhani Ulansari ${ }^{2}$ \\ Fakultas Ilmu Komputer dan Teknologi Informasi, Universitas Gunadarma \\ Fakultas Teknologi Informasi, Universitas Respati Indonesia \\ ramadhani.ulansari@fti.urindo.ac.id
}

\begin{abstract}
Abstrak: Udara merupakan bagian terpenting bagi semua makhluk hidup. Pada udara terdapat beberapa gas yang membuat makhluk hidup bertahan hidup, maka dari itu kualitas udara sangat berpengaruh bagi makhluk hidup di muka bumi ini. Seiring perkembangan zaman, kualitas udara yang baik kini kian sulit untuk ditemukan terutama pada wilayah perkotaan apalagi yang memiliki kawasan industri. Oleh karena itu, diperlukan informasi tentang kualitas udara agar pekerja industri dapat mengetahui kualitas udara yang mereka hirup. Pada penelitian ini akan di monitoring udara yang ada dalam suatu industri. Zat pencemar udara yang dipantau yaitu gas LPG, gas CO dan asap menggunakan ESP8266 NodeMCU, buzzer dan ThingSpeak yang nanti hasilnya akan diperlihatkan di website.
\end{abstract}

Kata Kunci: Gas, Helm, IoT, NodeMCU, Sensor, ThingSpeak

\section{PENDAHULUAN}

Seiring perkembangan zaman, kualitas udara yang baik kini kian sulit untuk ditemukan terutama pada wilayah perkotaan apalagi yang memiliki kawasan industri. Kualitas udara tersebut terganggu dengan adanya pabrik-pabrik, polusi, asap pembakaran, dan lain-lain. Oleh karena itu perlunya pemantauan kualitas udara agar dampak negatif dari pencemaran udara dapat diminimalisir. Berdasarkan Keputusan Menteri Kesehatan RI nomor 1407 tahun 2002 tentang Pedoman Pengendalian Dampak Pencemaran Udara, pencemaran udara adalah masuknya atau dimasukkannya zat, energi, dan/atau http://ejournal.urindo.ac.id/index.php/TI komponen lain ke dalam udara oleh kegiatan manusia, sehingga mutu udara turun sampai ke tingkat tertentu yang menyebabkan atau mempengaruhi kesehatan manusia[1].

Jenis-jenis bahan pencemar udara didasarkan pada baku mutu udara yang dihirup sehari-hari menurut Peraturan Pemerintah Nomor 41 tahun 1999, meliputi sulfur dioksida $\left(\mathrm{SO}_{2}\right)$, karbon monoksida $(\mathrm{CO})$, nitrogen dioksida $\left(\mathrm{NO}_{2}\right)$, ozon $\left(\mathrm{O}_{3}\right)$, hidrogen karbon (HC), PM-10, PM2.5, TSP (debu), $\mathrm{Pb}$ (timah hitam), dan debu jatuh[2]. Dengan berkembangnya industri membuat semakin banyak gas gas berbahaya yang dihasilkan oleh industri. Sebelumnya telah 
dilakukan penelitian tentang monitoring polusi udara.

\section{TINJAUAN PUSTAKA}

Menurut Fauzi (2011:1) Mikrokontroler adalah sebuah chip yang berfungsi sebagai pengontrol rangkaian elektronik dan umumnya dapat menyimpan program di dalamnya. Mikrokontroler dibangun dari elemen-elemen dasar yang sama dengan komputer pribadi atau komputer mainframe. Mikrokontroler digunakan dalam produk dan alat yang dikendalikan secara otomatis, seperti sistem kontrol mesin, remote control, mesin kantor, peralatan rumah tangga, alat berat, dan mainan, dengan mengurangi ukuran, biaya, serta konsumsi tenaga dibandingan dengan mendesain menggunakan mikroprosesor memori, dan alat input output yang terpisah[3].

NodeMCU adalah sebuah platform IoT (Internet Of Things) yang bersifat open source. Terdiri dari perangkat keras berupa System On Chip ESP8266 dari ESP8266 buatan Esperessif System. NodeMCU merupakan papan pengembangan yang dengan Firmware berbasiskan eLua dan System on a Chip (SoC) ESP8266-12E. ESP8266 sendiri merupakan chip WiFi dengan protocol stack TCP/IP yang lengkap. Sebelumnya telah dilakukan penelitian tentang monitoring polusi udara[4]. Pada penelitian "RANCANGAN APLIKASI PENGUKUR
TINGKAT POLUSI UDARA BERBASIS ARDUINO UNO R3 DAN WEB". Pada penelitian tersebut sensor yang digunakan yaitu MQ-7 yang berfungsi untuk mengukur konsentrasi gas karbon monoksida (CO). Tetapi hanya mengukur gas karbon monoksida saja. Pada perancangan ini penulis akan membuat monitoring pada gas CO, LPG dan asap dengan sensor MQ-2[1].

\section{METODE PENELITIAN}

Pada alat ini memiliki 3 blok, yaitu blok Input, blok Proses, dan blok Output. Aktivator digunakan untuk mengaktifkan seluruh blok - blok lainnya. Blok Input sebagai blok yang menjadi perintah masukan ke mikrokontroller. Blok Proses yang memproses inputan dan akan memproses dan mengirim hasilnya ke blok output. Blok Output sebagai blok hasil keluaran dari seluruh rangkaian. Secara rinci akan dijelaskan sebagai berikut.

\section{AKTIVATOR}

Sumber tegangan berfungsi untuk mengaktifkan komponen pada alat, dimana sumber tegangan yang diberikan sebesar $12 \mathrm{~V}$. Sumber tegangan dapat diperoleh dari Power Supply, baterai, adaptor, aki, dll. Setelah itu tegangan $12 \mathrm{~V}$ dimasukan ke regulator yang berfungsi sebagai pengubah dan penstabil tegangan agar dapat mendapatkan hasil keluaran berupa tegangan $5 \mathrm{~V}$. Tegangan $5 \mathrm{~V}$ ini untuk 
mengaktifkan sensor MQ-2 dan membangkitkan daya NodeMCU.

\section{BLOK INPUT}

Pada blok inputan yang digunakan yaitu sensor MQ-2. MQ-2 akan mengirimkan sinyal tegangan ke NodeMCU kadar gas yang terdeteksi.

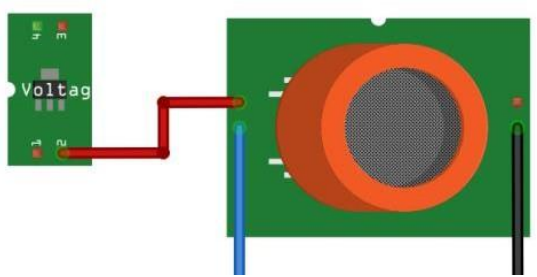

Gambar 1. Rangkaian input

\section{BLOK PROSES}

Pada blok proses terdapat mikrokontroller ESP8266 NodeMCU. NodeMCU akan membaca sinyal perintah yang diterima oleh Sensor yang masuk melalu pin Analog In yang terdiri dari 1 masukan dari sensor. fritzing

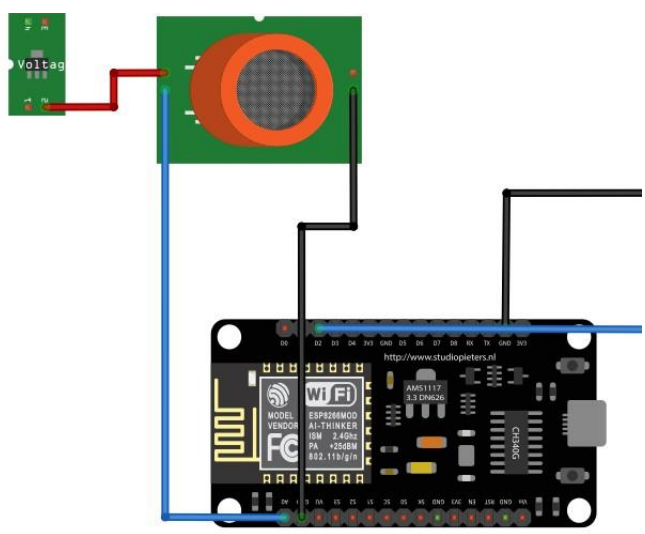

Gambar 2. Rangkaian blok proses

\section{BLOK OUTPUT}

Pada blok output ini adalah ThingSpeak dan buzzer. ThingSpeak berguna sebagai penampil data dari sensor MQ-2 dan buzzer berfungsi sebagai penanda. Setelah data diterima oleh ThingSpeak, ThingSpeak akan memproses data tersebut dan menampilkannya dalam bentuk grafik. Buzzer digunakan sebagai penanda jika ada gas, jika terdeteksi gas maka buzzer akan menyala.

Gambar 3. Rangkaian blok output

\section{HASIL DAN PEMBAHASAN}

Rancang Bangun Helm Monitoring Udara Pada Industri Berbasis Internet of Things Menggunakan ESP8266 NodeMCU yang 
memiliki 2 kondisi, yaitu : standby dan terdeteksi gas berbahaya.

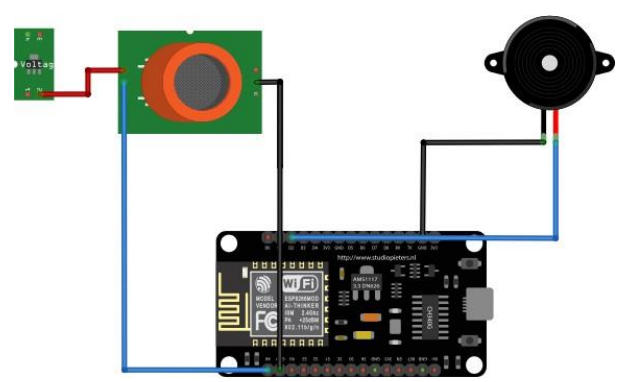

Gambar 5. Skematik rangkaian

Pada blok input, arus akan mengaktifkan komponen sensor MQ-2. Sensor MQ-2 yang diletakkan pada pin A0 NodeMCU ini akan menerima kadar udara terus menerus dan mengirim hasil kualitas udaranya ke ThingSpeak.

Pada blok proses, NodeMCU akan memproses data tersebut dan mengirim hasil udara ke ThingSpeak melalui sambungan Wi-Fi.

Pada blok output, ThingSpeak akan menampilkan data data dari kandungan gas CO, LPG dan asap yang diterima sensor dan buzzer yang diletakkan pada pin D2 NodeMCU akan mengeluarkan bunyi. Jika terdeteksi gas LPG, CO atau LPG maka sensor akan mengirim data ke NodeMCU untuk di proses lalu mengirim data ke ThingSpeak dan membunyikan buzzer.
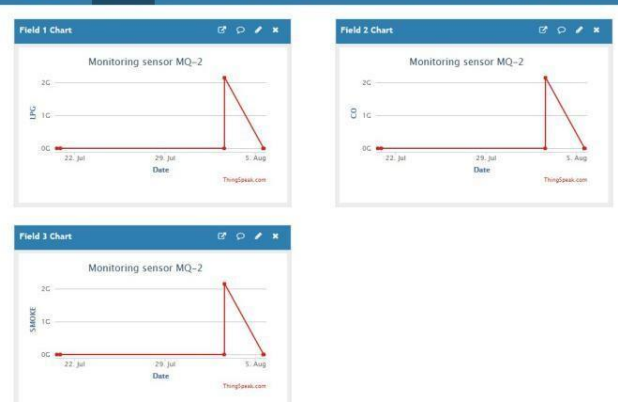

Gambar 6. Tampilan pada ThingSpeak

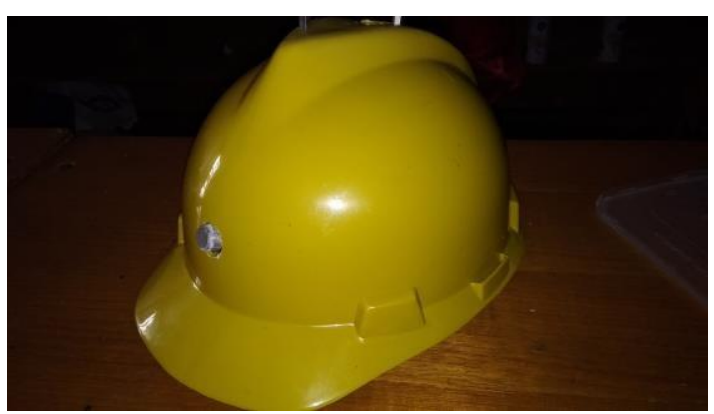

Gambar 7. Tampilan alat helm monitoring udara 


\begin{tabular}{|c|c|c|}
\hline $\begin{array}{l}\text { KONDISI } \\
\text { UDARA }\end{array}$ & $\begin{array}{c}\text { KADAR } \\
\text { KONSEN } \\
\text { TRASI }\end{array}$ & OUTPUT \\
\hline Bersih & - & $\begin{array}{c}\text { Buzzer Mati, Data Kadar } \\
\text { Hasil Udara Terkirim Ke } \\
\text { Thingspeak }\end{array}$ \\
\hline Gas Lpg & Pekat & $\begin{array}{c}\text { Buzzer Menyala, Data } \\
\text { Kadar Hasil Udara } \\
\text { Terkirim Ke Thingspeak }\end{array}$ \\
\hline Gas Lpg & $\begin{array}{l}\text { Kurang } \\
\text { Pekat }\end{array}$ & $\begin{array}{c}\text { Buzzer Mati, Data Kadar } \\
\text { Hasil Udara Terkirim Ke } \\
\text { Thingspeak }\end{array}$ \\
\hline Asap & Pekat & Buzzer Menyala, Data \\
\hline $\begin{array}{c}\text { Pembakara } \\
\mathrm{n}\end{array}$ & & $\begin{array}{c}\text { Kadar Hasil Udara } \\
\text { Terkirim Ke Thingspeak }\end{array}$ \\
\hline Asap & Kurang & Buzzer Mati, Data Kadar \\
\hline $\begin{array}{c}\text { Pembakara } \\
\mathrm{n}\end{array}$ & Pekat & $\begin{array}{c}\text { Hasil Udara Terkirim Ke } \\
\text { Thingspeak }\end{array}$ \\
\hline
\end{tabular}

\section{PENUTUP}

\section{SIMPULAN DAN SARAN}

Berdasarkan perancangan, pengujian dan analisis yang telah dilakukan, maka didapatkan beberapa point kesimpulan, diantaranya sebagai berikut :

1. Setelah langkah-langkah uji coba dilakukan, alat dapat berfungsi dengan baik.

2. Rancangan ini dapat dikembangkan dalam sektor lain seperti pertambangan, perumahan, dll.

http://ejournal.urindo.ac.id/index.php/TI
3. Kemampuan ukur sensor MQ-2 dalam mengukur kadar udara baik sekali, bahkan dalam ruangan terbuka sekalipun dapat dideteksi kadar udaranya.

4. ThingSpeak yang digunakan membuat pekerjaan dalam membuat alat IoT semakin mudah, karena hanya perlu memakai API saja untuk mengirimkan datanya.

Dalam pembuatan dan hingg ketahap uji coba alat, penulis mendapatkan kendala yang dirasakan dapat diatasi dengan memperhatikan hal-hal sebagai berikut :

1. Ditambahkan sensor lain seperti untuk memantau suhu udara, kadar debu atau dapat diterapkan lagi pada peralatan yang lain. 


\section{DAFTAR PUSTAKA}

[1] Handayani, Sri,. Hadiansa, Atma,. Masrizal. (2017). "RANCANGAN APLIKASI PENGUKUR TINGKAT POLUSI UDARA BERBASIS ARDUINO UNO R3 DAN WEB." MEDIA INFORMATIKA BUDIDARMA. $1,3$.

[2] Oktaviana Sari, Linna,. Safrianti, Ery,. Sirait, Rummi. (2014). "ANALISA RESPON DAN SENSITIFITAS ALAT DETEKSI KADAR POLUTAN KARBON MONOKSIDA (CO) DI UDARA DENGAN SENSOR TGS 26." Arsitron. 5, 1.
[3] Abdul Kodir. (2013). Panduan praktis mempelajari aplikasi mikrokontroler dan pemrogramannnya menggunakan arduino. Andi Publisher: Jakarta.

[4] Pratiwi, Nana Dwi. Apa itu Module NodeMCU ESP8266?. URL

https://www.nyebarilmu.com/a pa-itu-module-nodemcuesp8266/. Diakses tanggal 8 Agustus 2018. 